The Influence of Interfaces on the Rates of Crosslinking in Poly(Dimethyl Siloxane) Coatings

T.R.E. Simpson, ${ }^{\mathrm{a}}$ Z. Tabatabaian, ${ }^{\mathrm{b}}$ C. Jeynes, ${ }^{\mathrm{b}}$ B. Parbhoo, ${ }^{\mathrm{b}}$ and J.L. Keddie ${ }^{\mathrm{a}}$ aapepartment of Physics, University of Surrey, Guildford, Surrey, GU2 7XH, UK

${ }^{\mathrm{b}}$ University of Surrey Ion Beam Centre, Guildford, Surrey GU2 7XH, UK

${ }^{\mathrm{c}}$ New Ventures R\&D, Dow Corning Ltd., Cardiff Road, Barry, S. Glamorgan, CF63 2YL, UK

Brief Abstract: The reaction rate of an $\mathrm{SiH}$ crosslinker in coatings of poly(dimethyl siloxane) (PDMS) has been found to vary with the type of substrate. The reaction rate in a $2.5 \mu \mathrm{m}$ thick coating on a PDMS substrate, determined using a new method of infrared ellipsometry, is 16 times greater than in the same coating on the native oxide of silicon. Intermediate rates are found on poly(styrene) and on poly(ethylene terephthalate) substrates. The polar contribution to the surface energy is found to be greater in those substrates having lower rates of reaction. We propose that the polar surfaces more strongly attract the Pt catalyst and form complexes that inhibit the $\mathrm{SiH}$ reaction rate. 


\title{
The Influence of Interfaces on the Rates of Crosslinking in Poly(Dimethyl Siloxane) Coatings
}

\author{
T.R.E. Simpson ${ }^{a}$, Z. Tabatabaian ${ }^{b}$, C. Jeynes $^{b}$, B. Parbhoo ${ }^{c}$, and J.L. Keddie ${ }^{a *}$ \\ ${ }^{\text {a} D e p a r t m e n t ~ o f ~ P h y s i c s, ~ U n i v e r s i t y ~ o f ~ S u r r e y, ~ G u i l d f o r d, ~ S u r r e y, ~ G U 2 ~ 7 X H, ~ U K ~}$ \\ ${ }^{\mathrm{b}}$ University of Surrey Ion Beam Centre, Guildford, Surrey GU2 7XH, UK \\ ${ }^{\mathrm{c}}$ New Ventures R\&D, Dow Corning Ltd., Cardiff Road, Barry, S. Glamorgan, CF63 \\ 2YL, UK
}

\begin{abstract}
We determine with infrared spectroscopic ellipsometry (IRSE) how the nature of the interface between a thin poly(dimethyl siloxane) (PDMS) coating and its substrate affects the rate of PDMS crosslinking reactions. Reactions between vinyl $\left(-\mathrm{CH}=\mathrm{CH}_{2}\right)$ end groups on PDMS and $\mathrm{SiH}$ groups in a crosslinker, i.e. a hydrosilylation crosslinking reaction, as well as between $\mathrm{SiH}$ groups and silanol groups, during the so-called "post-cure" crosslinking stage, are probed in situ at $85{ }^{\circ} \mathrm{C}$ using IRSE. The overall consumption of $\mathrm{SiH}$ follows first-order reaction kinetics. The first-order reaction coefficient $k_{1}$ for the hydrosilylation crosslinking reaction is the same for coatings on three different substrates: the native oxide of silicon $\left(\mathrm{SiO}_{2} / \mathrm{Si}\right)$; poly(styrene) (PS); and poly(ethylene terephthalate) (PET). For the slower post-cure reactions, however, the rate of $\mathrm{SiH}$ consumption depends on the substrate. In $2.5 \mu \mathrm{m}$ PDMS coatings on PS, $k_{1}$ is about seven times greater than in the same coating on $\mathrm{SiO}_{2} / \mathrm{Si}$. In PDMS coatings on a PDMS substrate, when the effect of the interface is
\end{abstract}

\footnotetext{
${ }^{*}$ Author to whom correspondence should be addressed. E-mail:

j.keddie@surrey.ac.uk Tel: +44 1483 686803; Fax: +44 1483686781
} 
thus minimal, $k_{1}$ is 16 times higher than on $\mathrm{SiO}_{2} / \mathrm{Si}$. The dependence of $k_{1}$ on the type of interface is probably the result of the interfacial segregation and complexation of the Pt catalyst for the post-cure reactions. Pt depth profiles obtained using Rutherford backscattering spectrometry show that the Pt has a higher concentration at the silicone/substrate interface compared to in the bulk for polar substrates. The polar contribution to the surface energy is found to be greater in those substrates that result in a lower $k_{1}$. We propose that the polar surfaces more strongly attract the Pt and form complexes that inhibit the post-cure reactions.

Keywords: silicones; coatings; crosslinking; interfaces; infrared ellipsometry; catalysts

\section{Introduction}

Silicones (i.e. polysiloxanes) in the form of elastomers, coatings and films find numerous important applications, such as encapsulants in electronics, biocompatible coatings on medical devices [1-3], oxygen-resistant coatings on spacecraft [4,5], and release liners for dispensing pressure-sensitive adhesives commonly used in tapes and labels [6,7]. These applications rely not only on the bulk physical and chemical properties of silicones but also on their fast and complete rate of cure. The cure characteristics of silicone coatings have been found empirically to depend on the nature and type of substrate, but the mechanisms and reasons for this dependence have not been reported in the open literature. This lack of basic understanding is a primary motivation for the research presented here.

Many industrial applications require fast-curing silicone systems that homogeneously crosslink throughout the bulk of the material. Systems that rely on hydrosilylation 
reactions very effectively meet this need. The reaction is usually catalysed by a platinum complex. The temperature, the level of catalyst, and the molar ratio of crosslinker to reactive group all allow the control of the final performance of the silicone product.

Many applications rely on the elasticity imparted by a three-dimensional silicone network, which is usually formed by the crosslinking of linear poly(dimethyl siloxane) (PDMS) or similar silicone molecules. The performance of a coating, especially its mechanical [6,8] and adhesion [7] properties, is governed by the extent of crosslinking and by any residual chemical groups in the bulk material and at interfaces. There are numerous methods to measure the reaction rates in bulk crosslinking polymer networks [9], but they cannot be easily applied to thin films and coatings. As a result, knowledge of crosslinking kinetics and mechanisms in PDMS is mainly drawn from studies of the bulk material [10], with much less work being performed on thin films.

Over the past few decades, many polymer scientists have discovered the profound impact of interfaces on polymer structure and dynamics [14]. There are two key reasons why the coating/substrate interface might influence the kinetics of crosslinking and curing in thin silicone coatings, as described below.

(1) Surface segregation. To lower interfacial energy, a reactive component in a silicone formulation might segregate to the interface with the substrate [14]. As a result, there will be a depletion of the component in the bulk and an excess concentration at the interface. Silicones typically contain a catalyst to speed up 
reactions and an inhibitor to control the catalysis rate. If this fine balance is upset by surface segregation of either the catalyst or the inhibitor, the rates of the reactions are likely to be affected. Other work [10] has already proven that the polymerisation rate is linearly proportional to the catalyst concentration.

(2) Chemical reactions with a substrate. The presence of an interface with a substrate opens up the possibility of reactions that will compete with the silicone's crosslinking reactions. SiH groups, which are contained in the crosslinker used in the present study, are known to be reactive with silanol ( $\mathrm{SiOH})$ or hydroxyl groups on a substrate [9]. Elsewhere, it has been found that $\mathrm{SiOH}$ chain ends will bond to interfacial hydroxyl groups [15], which in turn will restrict transport of molecules at the interface.

Clearly there is a need for a technique to examine crosslinking and curing in silicone thin films and coatings, as a means to determine whether the interface with a substrate has an important influence. Although transmission infrared (IR) spectroscopy and attenuated reflection IR spectroscopy are routinely employed to probe chemical reactions in thin films and coatings [16], their use is restricted to substrates that are transparent to IR radiation. A key advantage of IRSE is that it allows the use of any substrate, provided that it is smooth and planar. Better results are obtained, however, with substrates that are highly reflective of IR radiation [5]. It is only within the past few years that IR ellipsometry has been applied to the study of organic films and coatings [13].

In the silicone studied here, the silyl ( $\mathrm{SiH}$ ) groups of the crosslinker react with vinyl groups on PDMS through the hydrosilylation reaction. Simultaneously, but at a much 
slower rate, $\mathrm{SiH}$ groups are consumed through secondary crosslinking reactions that occur between $\mathrm{SiH}$ and $\mathrm{SiOH}$ groups newly-formed by the hydrolysis of $\mathrm{SiH}$ groups. (Some $\mathrm{SiH}$ groups might also react with chemical functionalities present on the surface of the substrate.) These secondary reactions are favoured when an excess of $\mathrm{SiH}$ over vinyl functionalities is used, and mainly occur after the completion of the primary hydrosilylation reaction. In this paper, we will refer to the hydrosilylation reaction as the "crosslinking reaction" and to the secondary reactions that consume SiH as "post-cure reactions" to be consistent with previously-used terminology [11].

Our previous work [11] has shown that when a silicone is confined to a thin coating (less than $15 \mu \mathrm{m}$ ) on a silicon substrate, the rates of the crosslinking reactions differ from the bulk behaviour. Using infrared spectroscopic ellipsometry (IRSE) [12,13], our experiments showed that the total time for the crosslinking reaction increases with film thickness. The post-cure reaction (i.e. consumption of excess crosslinker) follows first-order reaction kinetics. The first-order reaction coefficient was found to decrease linearly with increasing coating thickness up to a value of about $15 \mu \mathrm{m}$, where a constant value is approached. The exact origin of this phenomenon was not determined, but it was attributed to water diffusion into the coating being the ratelimiting step.

Here we extend the use of IRSE to examine the reaction kinetics on four substrates: native oxide on silicon ( $\left.\mathrm{SiO}_{2} / \mathrm{Si}\right)$; poly(styrene) (PS); poly(ethylene terephthalate) (PET); and crosslinked PDMS. The surface polar groups and the surface free energies of these substrates differ greatly. Our work specifically addresses the influence of the interface with the substrate on the rate of crosslinking and post-cure reactions in 
PDMS films. PET is particularly relevant to study, because it is a common substrate in many industrial products, especially as the support for silicone release liners and as the backing for adhesive release layers [7]. The use of crosslinked PDMS as a substrate for a PDMS coating is a means of eliminating the influence of the interface, since the substances on either side of the interface are nearly identical.

\section{Experimental Materials and Methods}

\subsection{Materials}

Crosslinked silicone networks were created via the reaction between vinyl-terminated PDMS (hereafter designated as vinyl polymer) and a trimethylsilyl-terminated poly(hydrogen methyl siloxane) crosslinker $\left[\left(\mathrm{CH}_{3}\right)_{3} \mathrm{Si}-\mathrm{O}-\left\{\mathrm{SiH}\left(\mathrm{CH}_{3}\right)-\mathrm{O}\right\}_{25}-\mathrm{Si}\left(\mathrm{CH}_{3}\right)_{3}\right]$, both in the presence of a Pt catalyst complex and an inhibitor. The vinyl polymer, with a nominal chemical formula of $\left[\mathrm{CH}_{2}=\mathrm{CH}-\mathrm{Si}\left(\mathrm{CH}_{3}\right)_{2}-\mathrm{O}-\left\{\mathrm{Si}\left(\mathrm{CH}_{3}\right)_{2}-\mathrm{O}\right\}_{150^{-}}\right.$ $\left.\mathrm{Si}\left(\mathrm{CH}_{3}\right)_{2}-\mathrm{CH}=\mathrm{CH}_{2}\right]$, has an average degree of polymerisation of 150 . The formulation contained 0.15 wt.\% of 1-ethynylcyclohexanol $\left[\mathrm{CH} \equiv \mathrm{C}-\mathrm{C}(\mathrm{OH})-\left(\mathrm{CH}_{2}\right)_{5}\right]$ to function as the catalyst inhibitor.

Silicone formulations were prepared by thorough mixing of crosslinker and vinyl polymer, followed by addition of the catalyst. The weight ratios of crosslinker to vinyl group ( $-\mathrm{CH}=\mathrm{CH}_{2}$ designated hereafter as $\mathrm{SiVi}$ ) were set to either 1:0.012 or 1:0.038. These ratios yield a molar ratio of $\mathrm{SiH}: \mathrm{SiVi}$ : of $1: 1$ and 3.2:1, respectively. The Pt metal concentration was maintained at $120 \mathrm{ppm}$ in both formulations by fixing the mass ratio of the formulation to the catalyst at 1:0.024. 


\subsection{Film Deposition}

All silicone coatings were deposited by spin-coating fresh formulations using a photoresist spin-coater (Cammax Precima Ltd., Colchester, UK). Four types of substrates were used: (1) IR-reflective, p-doped silicon wafers with an orientation of $<100>$, used as received; (2) PS thin films (ca. 75 nm thick) spin-coated onto the IRreflective Si wafers; (3) PET thin films (ca. $75 \mathrm{~nm}$ thick) spin-coated onto the Si wafers; and (4) cross-linked PDMS films (ca. $150 \mathrm{~nm}$ thick) also spin-coated onto the $\mathrm{Si}$ wafers. In all cases, there was a native $\mathrm{SiO}_{2}$ layer with a typical thickness of $2 \mathrm{~nm}$ on the surface of the Si substrates.

The PS films were cast from a $2 \% \mathrm{w} / \mathrm{w}$ solution in toluene at $4000 \mathrm{rpm}$. The PS (Polymer Laboratories, UK) had a weight-average molecular weight $M_{w}$ of $3.20 \times 10^{5}$ $\mathrm{g} \mathrm{mol}^{-1}$ and a polydispersity $\left(M_{w} / M_{n}\right)$ of 1.04 . It is glassy at the temperatures of these experiments. The PET films were cast from a $6 \% \mathrm{w} / \mathrm{w}$ solution in trifluoroacetic acid at the same rate of spinning. The PET was obtained as thick films from DupontTeijin Films. The PS and PET films were annealed in vacuum at $140{ }^{\circ} \mathrm{C}$ prior to their use as substrates, in order to achieve a solvent-free, equilibrated material. The silicone films were cast from a 5\% w/w solution of silicone cross-linking formulation (SiH:SiVi = 3.2:1, described in section 2.1) from n-pentane at $4000 \mathrm{rpm}$. The silicone films were allowed to cure fully for 24 hours at room temperature prior to their use as substrates.

One of two methods was used to vary the thickness of the spin-cast silicone films: (1) dilution of the silicone in solvent and (2) adjustment of the spin rate and time. The 
silicone formulation was diluted in analar-grade n-pentane to concentrations of 20, 40 or 70 vol.\%. The spin rate and times were $1900 \mathrm{rpm}$ for 10 s, $2000 \mathrm{rpm}$ for $10 \mathrm{~s}, 2000$ rpm for 10s, $3000 \mathrm{rpm}$ for $60 \mathrm{~s}$, and $4000 \mathrm{rpm}$ for $60 \mathrm{~s}$. By using various combinations of these parameters, silicone films with thicknesses ranging from 2.5 $\mu \mathrm{m}$ to $27 \mu \mathrm{m}$ were thereby deposited. Previous work [11] has shown that the method of deposition does not have an influence on the rate of crosslinking or curing.

\subsection{In Situ Ellipsometry Analysis of Crosslinking Reactions}

An FTIR spectroscopic ellipsometer (Model GESP5-FTIR, SOPRA Sa., BoisColombes, France) was used to analyse the reactions in the silicone films on the various substrates. A series of IRSE spectra were recorded over time until no further reduction in the $\mathrm{SiH}$ characteristic absorption peak at $2150 \mathrm{~cm}^{-1}$ [17] could be observed. The measurement time for each IRSE spectrum was typically 30 s. Spectra were recorded sequentially over the first 15 min. of the experiment, with an increasing time delay between subsequent measurements. All experiments were conducted in the ambient atmosphere of the laboratory with a relative humidity typically between 30 and $40 \%$ and a temperature between 21 and $23^{\circ} \mathrm{C}$. The substrates were placed on a hot-stage (Linkam Scientific Instruments Ltd, Tadworth, Surrey, UK) when performing measurements above room temperature. The thicknesses of thin PS, PET and silicone films were determined using a rotating-analyser spectroscopic ellipsometer (VASE, J.A. Woollam Co., Inc., Lincoln, NE, USA) in the visible range.

\subsection{Analysis of Reactions in Silicone Films}


A three-dimensional silicone network is created via the hydrosilylation reaction between the SiVi of the polymer and the $\mathrm{SiH}$ groups of the crosslinker, which is represented as:

$$
\begin{aligned}
& \sim-\mathrm{Si}-\mathrm{H}+\mathrm{CH}_{2}=\mathrm{HC}-\mathrm{Si}-\sim \stackrel{\text { Pt catalyst }}{\longrightarrow} \sim-\mathrm{Si}-\mathrm{CH}_{2}-\mathrm{CH}_{2}-\mathrm{Si}-\sim \\
& \text { heat }
\end{aligned}
$$

The nature and concentration of both the catalyst and the inhibitor, as well as the concentration of vinyl and $\mathrm{SiH}$ groups $[9,10]$, influence the reaction rate. At high temperature (ca. $150{ }^{\circ} \mathrm{C}$ ) with a catalyst concentration of $120 \mathrm{ppm}(\mathrm{Pt})$ and in thin films (ca. $1 \mu \mathrm{m}$ or less), the hydrosilylation crosslinking reaction is completed within seconds [11].

Secondary reactions also occur $[9,18]$, and are especially favored with an excess of crosslinker and during the so-called "post-cure" stage. The mechanism of this reaction first requires the catalysed hydrolysis of SiH groups:

$$
\sim-\mathrm{Si}-\mathrm{H}+\mathrm{H}_{2} \mathrm{O} \underset{\text { heat }}{\stackrel{\text { Pt catalyst }}{\longrightarrow}} \sim-\mathrm{Si}-\mathrm{OH}+\mathrm{H}_{2}
$$

Crosslinking occurs in this post-cure stage via the creation of Si-O-Si bonds, when the newly-formed silanol groups ( $\mathrm{SiOH}$ ) catalytically react with remaining $\mathrm{SiH}$ groups:

$$
\sim \text {-Si-H }+\mathrm{HO}-\mathrm{Si} \sim \underset{\text { heat }}{\stackrel{\text { Pt catalyst }}{\longrightarrow}} \sim-\mathrm{Si}-\mathrm{O}-\mathrm{Si} \sim+\mathrm{H}_{2}
$$

Another type of crosslinking reaction is the condensation of two silanol groups (which are created in reaction 2):

$$
\sim-\mathrm{Si}-\mathrm{OH}+\mathrm{HO}-\mathrm{Si} \sim \underset{\text { heat }}{\longleftarrow} \sim-\mathrm{Si}-\mathrm{O}-\mathrm{Si} \sim+\mathrm{H}_{2} \mathrm{O}
$$


The platinum-catalysed reactions (2) and (3) are slower than the primary crosslinking reaction (1). It is expected that the silanol condensation reaction (4) is even slower than the SiH reactions (2 and 3). Reactions 2, 3 and 4 are jointly referred to herein as "post-cure reactions" as they occur when the system is allowed, or forced, to proceed towards its complete conversion [9].

The extents of both (a) the hydrosilylation reaction (when the number ratio of $\mathrm{SiH}$ groups to vinyl groups in the mixture was $1: 1$ ) and (b) the post-cure reaction (when the number of $\mathrm{SiH}$ groups per $\mathrm{SiVi}$ group in the mixture was 3.2:1) were determined by analysing the changes in the $\mathrm{SiH}$ characteristic absorption $\left(2150 \mathrm{~cm}^{-1}\right)$ as a function of time. Details of the analysis have been given elsewhere [11].

\subsection{Rutherford Backscattering Spectrometry (RBS)}

Rutherford backscattering spectrometry was used to determine the concentration of Pt as a function of depth in the silicone films on two different substrates: $\mathrm{SiO}_{2} / \mathrm{Si}$ and PS. The usual silicone formulation, as given in Section 2.1, contains $\mathrm{Pt}$ at a concentration of $120 \mathrm{ppm}$ by weight (120 $\mu \mathrm{g}$ Pt per g of PDMS). (The atomic concentration of Pt cannot be calculated because the chemical formula of the Pt complex is not known.) In fact, these films had a Pt content of about 0.0011 at.\% (11 ppm), as measured by RBS, and this is very near the RBS detection limit for Pt in this material. Consequently, the films for RBS analysis were prepared with a nominal Pt concentration of 360 ppm by weight, in order to increase the statistical significance of the RBS data. 
Coatings with two different concentrations of SiH crosslinker were studied with RBS. These concentrations produced $\mathrm{SiH}: \mathrm{SiVi}$ ratios of $1: 1$ and $3.2: 1$, being the same values used in IRSE experiments to study crosslinking and post-cure reactions, respectively. Coatings with a $\mathrm{SiH}: \mathrm{SiVi}$ ratio of 1:1 were allowed to crosslink at room temperature for several weeks prior to RBS analysis. Coatings with a $\mathrm{SiH}: \mathrm{SiVi}$ ratio of $3.2: 1$, on the other hand, were heated to $80^{\circ} \mathrm{C}$ for three hours to crosslink and cure them. The average thickness of coatings used for RBS was $2.5 \mu \mathrm{m}$.

The principles of RBS have been described elsewhere [19]. The experiments were conducted with a $3.06 \mathrm{MeV}^{4} \mathrm{He}^{+}$beam with a beam current of approximately $30 \mathrm{nA}$, using a detector with a solid angle of $3.5 \mathrm{msr}$ at a scattering angle of $147^{\circ}$. This rather high beam energy was used so that the Pt signal at the buried interface had only a pileup background, resulting in more reliable data analysis. A charge of $60 \mu \mathrm{C}$ or more was collected in each measurement over a sample area of about $3 \mathrm{~mm}^{2}$.

No significant change in the Pt profiles throughout a measurement was seen, indicating that the silicone films were resistant to beam damage. Dose-rate dependent ion beam damage was not observed. Data analysis was achieved with the DataFurnace code [20].

\subsection{Surface Energy Measurements}

The surface energy $\gamma$ of each of the substrates $\left(\mathrm{SiO}_{2} / \mathrm{Si}\right.$, PET, PS, and PDMS) used in the IRSE and RBS experiments was measured. The substrates were prepared by the same procedure used previously. The equilibrium contact angles of $1 \mu \mathrm{L}$ sessile drops of both water and diiodomethane were independently measured for each of the 
substrates. These measurements were converted into surface energy values via the geometric-mean approach developed by Owens and Wendt [21]. Both the polar $\left(\gamma^{p}\right)$

and the dispersive $\left(\gamma^{\mathrm{d}}\right)$ components of $\gamma\left(\right.$ with $\gamma^{\mathrm{p}}+\gamma^{\mathrm{d}}=\gamma$ ) were determined by this technique.

\section{Results and Discussion}

In Section 3.1 we describe briefly the methodology used to determine the extent of crosslinking and cure through the analysis of changes in the characteristic $\mathrm{SiH}$ stretching absorption of the crosslinker and the derivation of the first-order reaction coefficient. In Section 3.2, we consider the effect of the coating/substrate interface on the kinetics of a system in which the SiH:SiVi ratio is 1:1. Then in Section 3.3, we consider the case when the $\mathrm{SiH}: \mathrm{SiVi}$ ratio is $3.2: 1$, which is in excess of what is needed by stoichiometry for the reaction. Evidence for the segregation of $\mathrm{Pt}$ at the silicone/substrate interface is presented in Section 3.4. Finally, in section 3.5 we consider possible mechanisms for the observed interfacial effects, taking into account the $\gamma_{p}$ of the substrates.

\subsection{In Situ IRSE Analysis of Silicone Reactions}

IRSE is used to monitor the change in concentration of $\mathrm{SiH}$ groups in silicone coatings undergoing crosslinking and post-cure reactions by measuring the ellipsometry parameters ( $\psi$ and $\Delta$ ) as a function of time. Figure 1 shows the spectra obtained from a thin silicone coating on a PS substrate at the start of curing at $80{ }^{\circ} \mathrm{C}$. The characteristic absorptions of PDMS are readily seen at the expected frequencies, as delineated in the figure caption. Characteristic absorptions associated with PS [22] can just be seen between $1450-1600 \mathrm{~cm}^{-1}$ (ring skeleton vibrations) and at 
approximately $3050 \mathrm{~cm}^{-1}$ (aromatic C-H stretches), although these are poorly resolved because the PS is a thin layer $(75 \mathrm{~nm})$ that is buried beneath the silicone. Using values of the silicone optical constants reported previously [11] from the bulk material, the thickness of the coating can be determined by modelling the data via standard methods $[4,5,12,23]$. In the transparent region of PDMS (between 1500 and $4000 \mathrm{~cm}^{-1}$, except around $2954 \mathrm{~cm}^{-1}$ ), interference fringes are observed. These are particularly helpful in determining film thickness. Analysis of the data in Figure 1 reveals that the silicone film thickness is $2.6 \mu \mathrm{m}$.

Of particular interest to this study of crosslinking through hydrosilylation and postcure reactions is the $\mathrm{SiH}$ spectral region $\left(2100-2200 \mathrm{~cm}^{-1}\right)$ [17]. It was found that the data in this region changed during the curing time, whereas there were no significant changes elsewhere. Figure 2 shows some representative spectra obtained over time from the same specimen as in Figure 1. At times later than 5.3 min. after the start of crosslinking, there were no changes observed in the spectra. It is concluded that after this time no further reaction involving the SiH group took place and that the SiH was fully consumed.

The amount of SiH groups in the silicone coating over time can be determined using a Bruggeman effective medium approximation (EMA) model [24]. This model predicts the optical constants for a blend of two or more substances by considering the optical constants of each. The first data set obtained at time $t=0$ represents the unreacted state; its reaction is defined as being " $0 \%$ complete”. A reaction is deemed to be “ $100 \%$ complete” at the point when the spectra does not change within the uncertainty of the measurement and the $\mathrm{SiH}$ is fully consumed. Optical constants were obtained 
from the $(\psi, \Delta)$ pairs at each wavelength for the "0\%" and "100\% complete" data sets. The data at intermediate times are then interpreted by mixing the optical constants of the "0\%" and "100\% complete" materials using the EMA model.

The solid lines in Figure 2 represent the curves of best-fit obtained using the Bruggeman EMA model assuming a certain percentage of completion. Through such an analysis, values for the extent of $\mathrm{SiH}$ consumption were thereby obtained as a function of time. A measurement of the completion time of the reactions could then be obtained, with an uncertainty that is set by the time interval between measurements and by the definition of the point of $100 \%$ completion. A more useful technique of analysis is to extract the reaction coefficient from the data, as described below.

In our previous work [11], the consumption of $\mathrm{SiH}$ was found to follow first-order reaction kinetics given as

$$
\frac{\mathrm{d}[\mathrm{SiH}]}{\mathrm{dt}}=-\mathrm{k}_{1}[\mathrm{SiH}],
$$

where $\left[\mathrm{SiH}\right.$ ] represents the concentration of $\mathrm{SiH}$ groups, and $k_{1}$ is the first-order reaction coefficient. Plots of $\ln [\mathrm{SiH}]_{\mathrm{t}} /[\mathrm{SiH}]_{0}$ (where the subscripts indicate time) as a function of cure time $t$ were found to be linear. This analysis was conducted for silicone coatings on the three types of substrates: $\mathrm{SiO}_{2} / \mathrm{Si}$; PS; and PET. Figure 3 shows a plot of $\ln \left([\mathrm{SiH}]_{\mathrm{t}} /[\mathrm{SiH}]_{0}\right)$ as a function of cure reaction time for silicone coatings (initial SiH:SiVi ratio of 3.2:1) with similar thicknesses $(\sim 2.5 \mu \mathrm{m})$ on Si and on PS substrates at $80{ }^{\circ} \mathrm{C}$. (The time is adjusted to take the hydrosilylation crosslinking reaction into account, as will be explained in Section 3.3.) The solid 
lines are the linear best fits to the data. The gradients of these lines yield $k_{1}$ for the cure reaction on the two different substrates. It can be seen that there is a large difference between the gradients for the two. The analysis finds values of $k_{1}$ of 107.2 x $10^{-5} \mathrm{~s}^{-1}$ for $\mathrm{SiO}_{2} / \mathrm{Si}$ and $699.5 \times 10^{-5} \mathrm{~s}^{-1}$ for PS, which is a difference of nearly a factor of seven. This influence of the substrate is explored in greater detail for the hydrosilylation and post-cure reactions in the next two sections.

\subsection{Hydrosilylation Crosslinking Rate when $\mathrm{SiH}: \mathrm{SiVi}=1: 1$}

As just pointed out, there is an apparent effect of the substrate on the value of $k_{1}$ for the consumption of $\mathrm{SiH}$ in the post-cure reactions. However, $\mathrm{SiH}$ is also consumed in the initial hydrosilylation reaction between $\mathrm{SiH}$ and $\mathrm{SiVi}$ (via Equation 1). In order to observe whether the interface is having an effect on the hydrosilylation reaction, it is necessary to reduce the amount of crosslinker in the formulation.

For a silicone formulation in which the molar ratio $\mathrm{SiH}: \mathrm{SiVi}$ is $1: 1$ and the thickness is $14.6 \mu \mathrm{m}$, it was found that the cure rate at $80{ }^{\circ} \mathrm{C}$ is fast and the consumption of $\mathrm{SiH}$ groups takes ca. 4 min. at a temperature. At this temperature, the reaction conversion rate was such that the IRSE data sampling time (30 s per spectrum) made a detailed kinetic study impossible to complete. Instead, experiments on a series of coatings were performed at room temperature where the reaction rate is slower.

Table 1 lists values of $k_{1}$ for the consumption of SiH obtained from these experiments. It is apparent from these values that, within the error of the measurement, the type of substrate has no effect on the hydrosilylation rate. The value of $k_{1}$ is the same for PDMS coatings on $\mathrm{SiO}_{2} / \mathrm{Si}$, on PS, and on PET. 


\subsection{Cure Kinetics when SiH is in Excess $(\mathrm{SiH}: \mathrm{SiVi}=3.2: 1)$}

When $\mathrm{SiH}$ groups are present in excess relative to $\mathrm{SiVi}$ groups within a coating, both the hydrosilylation and post-cure reactions occur. However, the data corresponding to the post-cure reactions can be corrected to take into account the initial time elapsed during which the hydrosilylation reaction primarily occurs. From measurements on films in which the $\mathrm{SiH}: \mathrm{SiVi}$ ratio was $1: 1$, an approximate completion time for the crosslinking reaction was obtained for a given temperature and film thickness. This hydrosilylation-completion time was then subtracted from the data for films in which the $\mathrm{SiH}$ was in excess. A reaction zero point for the cure reactions was thus obtained.

Figure 4 shows a plot of $k_{1}$ for the cure reaction at $80{ }^{\circ} \mathrm{C}$ as a function of coating thickness for silicone coatings on the four different types of substrates: $\mathrm{SiO}_{2} / \mathrm{Si}, \mathrm{PET}$, PS, and crosslinked PDMS. It can be seen that for all the substrates, $k_{1}$ decreases inversely with film thickness, and the lines of best fit converge as the thickness of the coating approaches $20 \mu \mathrm{m}$. This thickness dependence of $k_{1}$ on PDMS, PS and PET substrates is consistent with what was found previously [11] for the $\mathrm{SiO}_{2} / \mathrm{Si}$ substrate. The data suggest that there is a single value of $k_{1}$ for the bulk material, which can be defined as being thicker than about $20 \mu \mathrm{m}$. When the silicone is confined to a coating that is thinner than about $20 \mu \mathrm{m}$, the curing reaction is dependent on the coating thickness.

More interestingly, in the thinner films, there are significant differences in the values of $k_{1}$ between the four types of substrate. Table 2 lists $k_{1}$ values for curing in $2.5 \mu \mathrm{m}$ coatings. The magnitude of $k_{1}$ for the silicone coating on PS is seven times as large as 
that of $k_{1}$ for the coating on $\mathrm{SiO}_{2} / \mathrm{Si}$. An even greater difference is observed for the $2.5 \mu \mathrm{m}$ silicone coating on PDMS, with the magnitude of $k_{1}$ being sixteen times as large as that of $k_{1}$ for the coating on $\mathrm{SiO}_{2} / \mathrm{Si}$. It was hypothesised that the reason for the dependence of $k_{1}$ on the substrate is that the Pt catalyst is segregating to the interface with some substrates to a greater extent than others.

\subsection{Pt Concentration Profiles in Silicone Films by RBS}

RBS analysis was used to determine if there was any evidence for the segregation of the Pt catalyst to the interface with the substrate. With about 0.001 at.\% Pt concentration in the silicone film, the count rate from Pt atoms is very low, and the statistics of the measurement are consequently poor. With relatively thick PDMS films of about $2.5 \mu \mathrm{m}$, the depth resolution of the measurement is likewise poor, being on the order of $150 \mathrm{~nm}$ (corresponding to a thickness of $45 \mathrm{~nm}$ per data point).

In order to compare quantitatively the extent of Pt interfacial segregation, if any, the areal density of Pt in a 270 nm layer near the interface was determined for each silicone film. The results are summarized in Table 3, which lists the measured areal density of Pt above the concentration that is present in the bulk of the film. The uncertainty on the measurements is entirely due to counting statistics.

For coatings with a $\mathrm{SiH}: \mathrm{SiVi}$ ratio of $1: 1$, which were at $25^{\circ} \mathrm{C}$ during crosslinking, the RBS data showed an interfacial Pt concentration of $1.0 \times 10^{13}$ atoms $\mathrm{cm}^{-2}$ at the interface with $\mathrm{SiO}_{2} / \mathrm{Si}$. At the interface with PS, by comparison, there was no evidence for a Pt excess concentration. In coatings in which the $\mathrm{SiH}: \mathrm{SiVi}$ ratio is 3.2:1, which were heated at $80{ }^{\circ} \mathrm{C}$ for three hours, there is evidence for Pt segregation 
at the interface with both type of substrate. Within the uncertainty on the measurements, there is no significant difference in the Pt interfacial concentrations in coatings on $\mathrm{SiO}_{2} / \mathrm{Si}$ and on PS.

Considering that the atomic radius $r$ of $\mathrm{Pt}$ is $138.5 \mathrm{pm}$ [25], the maximum areal density of a Pt monolayer, $\rho=0.91 \pi^{-1} r^{-2}$, is estimated to be $2 \times 10^{15}$ atoms $\mathrm{cm}^{-2}$. It is therefore apparent that a complete Pt monolayer has not been formed in any of the silicone coatings. In fact, the upper limit of the observed excess interface Pt is about two orders of magnitude lower. In systems undergoing cure, the active Pt may be in a metallic or in an organosilicone-complexed form. The exact chemical structure of the co-ordinated Pt - whether in silicone or at an interface - is not known. However, if the Pt atoms were in a complex, then an interfacial layer of Pt as dense as $2 \times 10^{15}$ atoms $\mathrm{cm}^{-2}$ would not be possible because of simple steric considerations.

\subsection{Proposed Mechanism for Interfacial Effects}

We attribute the dependence of the post-curing reaction rate (in thin coatings) on the type of substrate (Table 2) to the interface attracting and inhibiting the Pt catalyst to varying degrees. It is therefore first relevant to consider what is already known about the Pt catalyst. Investigation of the mechanisms of the hydrosilylation reaction catalysed by the preferred complex of Pt reacting with divinyl tetramethyl disiloxane has revealed that the oxidation state of the Pt is 0 [26, 27]. An essential step in the reaction is the formation of Pt colloidal particles, with an average particle size of $2 \mathrm{~nm}$ [27]. 
A wide variety of chemical groups can interact with various magnitudes of bond strength with the Pt metal. Some groups are known to neutralise completely the Pt as a catalyst (and are therefore called poisons), whereas others are known to form complexes that can be thermally displaced and are thus called inhibitors. As examples, chemical groups possessing a lone pair of electrons, e.g. amines, sulphides, and phosphines, readily react with the Pt metal and poison the catalyst. Molecules bearing carboxylic groups, unsaturated groups and/or alcohol groups create complexes with the platinum catalyst that are stable at room temperature. The inhibition effect of such complexes is controlled by both the nature and the concentration of the groups. [9] The scientific, patent and commercial literature abound in examples of inhibitors and potential poisons of the platinum catalyst. However, the information is dispersed, and a comprehensive review has not been published, probably because of the intense commercial interest in these systems.

The presence of polar functionalities in high surface energy substrates offers potential binding sites for the complexation of metallic Pt, leading to inhibition of the reaction. At a temperature of $80{ }^{\circ} \mathrm{C}$, the mobility of the Pt catalyst will be relatively high so that transport to the interface is feasible. Furthermore, if Pt is segregated to an interface in a thin coating, then its concentration in the bulk must be depleted. A depletion of the Pt will reduce the rate of any reaction that it catalyzes. Varying degrees of Pt segregation and inhibition might explain the observed magnitudes for $k_{1}$ decreasing with substrate type as $\mathrm{PDMS}>\mathrm{PS}>\mathrm{PET}>\mathrm{SiO}_{2} / \mathrm{Si}$.

RBS shows, however, that Pt segregates to the interface with PS to a similar extent as to the interface with $\mathrm{SiO}_{2} / \mathrm{Si}$. It is therefore likely that there are differing degrees of 
catalyst inhibition at the two interfaces. A simple consideration of $\gamma_{\mathrm{p}}$ for the various substrates supports this argument. Our measurements found that $\gamma_{\mathrm{p}}$ of the substrates decreases in this order: $\mathrm{SiO}_{2} / \mathrm{Si}>\mathrm{PET}>\mathrm{PS} \approx \mathrm{PDMS}$, as shown in Table 4. The polar contribution of $\gamma$ is most relevant to consider here, because polar groups are prone to form complexes with Pt. The data in Table 4 show that $\mathrm{SiO}_{2} / \mathrm{Si}$ is a much more polar surface compared to PS, and therefore the inhibition at the interface with PS is probably weaker in comparison to the inhibition at the interface with $\mathrm{SiO}_{2} / \mathrm{Si}$. Thus, although the chemical groups at the origin of the polarity of the surfaces are very different in the four substrates, the polar contribution to the surface energy alone can potentially explain the varying extents of catalyst inhibition

The interface formed between the PDMS coating and "itself" on the PDMS substrate represents a limiting case. Since nearly the same material is on either side of the interface, any interfacial effects should be lost. Our measurements confirm that there are no polar groups on the PDMS surface that are capable of complexing with nearby Pt atoms. Hence, there is presumably no inhibition of the reaction rate, resulting in the largest observed magnitude for $k_{1}$. Somewhat surprisingly, $k_{1}$ for PS is lower compared to $k_{1}$ for PDMS, even though $\gamma_{\mathrm{p}}$ for the two surfaces is very low and comparable. Although no polar functionalities are present at the PS surface, the polymer is likely to contain free vinyl groups that are known to complex with $\mathrm{Pt}$ metal. Hence, any Pt catalyst near the interface with the PS would therefore be inhibited. RBS confirms that there is some Pt segregation at the interface. The postcure reaction is therefore faster on a PDMS substrate compared to a PS substrate, even though the $\gamma_{p}$ of the two surfaces is very low and comparable. 
Some simple order-of-magnitude calculations further support our explanation of the results. The total number of Pt atoms required to saturate an interface, using the radius for metallic Pt of 138.5 pm [25] and neglecting any complex formation, is estimated to be $2 \times 10^{15}$ atoms $\mathrm{cm}^{-2}$. We estimate from the composition of the formulation that there are $4 \times 10^{17}$ atoms $\mathrm{cm}^{-3}$ in a coating. Thus, the creation of a saturated Pt layer at the interface would deplete all of the Pt in a coating on the order of $50 \mu \mathrm{m}$ thick. Since the Pt is probably complexed at the interface, however, less Pt would in reality be needed to achieve a saturated layer. In any case, the calculation demonstrates that in thin coatings, any segregation (or inhibition) of Pt at the interface can significantly deplete the Pt concentration in the bulk of the coating.

For the hydrosilylation reaction between $\mathrm{SiVi}$ and $\mathrm{SiH}$ (1:1 ratio), rather than the postcure reactions, the type of substrate does not affect the first-order rate coefficient for the consumption of $\mathrm{SiH}$ (Table 1). As the reaction is relatively fast, it is likely that any segregation of the Pt catalyst to the interface with the substrate has not occurred within the hydrosilylation reaction, thereby removing any influence of the substrate on the rate constant. Moreover, even if there were some differences in the rate, the IRSE technique does not have sufficient time resolution to resolve them.

Regardless of the substrate, the post-curing reaction rate decreases as film thickness increases up to a thickness of about $20 \mu \mathrm{m}$ (Figure 4). The thickness dependence of $k_{1}$ is not affected by the substrate. The mechanism(s) responsible for this phenomenon cannot be determined from our data alone. Since there is no dependence on the substrate, however, interfacial segregation of Pt is not likely to be the cause of the thickness dependence. Instead, the phenomenon might be linked to transport of 
reacting species within the coating. As the coating thickness increases, the time required for water to diffuse through the entire coating also increases. Similarly, it will take longer for reaction products to diffuse out of the coating. If the transport is by Fickian diffusion, a characteristic time $\tau$ for diffusion in a coating of thickness $h$ is given as $\tau \propto \boldsymbol{h}^{2} / \boldsymbol{D}$, where $D$ is a concentration-dependent diffusion coefficient of the diffusing species. There is a large degree of experimental uncertainty in defining a time of reaction from our data. It is not possible to test the dependence of $\tau$ on $h$ with any confidence.

\section{Conclusions}

We have successfully used infrared spectroscopic ellipsometry to probe hydrosilylation and post-cure reactions via the loss of $\mathrm{SiH}$ groups in poly(dimethyl siloxane) coatings on $\mathrm{SiO}_{2} / \mathrm{Si}$, PET, PS and PDMS substrates. Both the hydrosilylation and the post-cure reactions follow first-order reaction kinetics in the consumption of $\mathrm{SiH}$ contained in the crosslinker. The type of substrate has no significant effect on the value of the first-order reaction coefficient, $k_{1}$, for the hydrosilylation crosslinking reaction at room temperature.

On the other hand, $k_{1}$ for the post-cure reaction at $80{ }^{\circ} \mathrm{C}$ varies significantly with the type of substrate, particularly in thinner films (ca. $2.5 \mu \mathrm{m})$. RBS analysis confirms that Pt catalyst in the PDMS segregates at the interface with both $\mathrm{SiO}_{2} / \mathrm{Si}$ and PS substrates, leading to some depletion of the Pt concentration in the bulk of the film. Measurements of the surface energy of the four substrates show that the value of $k_{1}$ increases as the polar contribution to the surface free energy decreases. We conclude that more strongly polar groups are prone to form complexes with the Pt catalyst and 
thereby inhibit the post-cure reactions. Although the PS surface does not contain polar groups, it is speculated that the presence of free vinyl groups might inhibit the catalysis. For a PDMS coating on a PDMS substrate, where the effect of the interface is essentially eliminated, there is minimal Pt segregation and catalyst inhibition, and so $k_{1}$ is the highest out of all four substrates.

\section{Acknowledgements}

The UK's Engineering and Physical Sciences Research Council provided funding for the IR ellipsometer, for T.R.E.S., and for the RBS at the Surrey Ion Beam Centre. We are grateful to Dow Corning and to DuPont-Teijin Films for donating the silicone materials and the PET, respectively.

\section{References}

1. Shimamoto, A.; Kanemitsu, S.; Fujinaga, K.; Takao, M.; Onoda, K.; Shimono, T.; Tanaka, K.; Shimpo, H.; Yada, I. Ann Thorac Surg 2000, 69, 115-120.

2. Ozbek, C.; Heisel, A.; Gross, B.; Bay, W.; Schieffer, H. Catheter Cardiovasc Diagn 1997, 41, 71-78.

3. Roberts, M. Nephrology 1998, 4, 243-245.

4. Bungay, C.L.; Tiwald, T.E.; Thompson, D.W.; DeVries, M.J.; Woollam, J.A.; Elman, J.F. Thin Solid Films 1998, 313-14, 713-717.

5. Yan, L.; Gao, X.; Bungay, C.; Woollam, J.A. J Vac Sci Technol A 2001, 19, 447454.

6. Kobayashi, K.; Takimoto, S.; Osawa, Z. Polymer Bull 1998, 41, 77-84. 
7. Jones, J.D.; Peters, Y.A. In Handbook of Pressure Sensitive Adhesive Technology, Satas D (ed). Van Nostrand Reinhold: New York, 1989; pp 601-624.

8. Villar, M.A.; Vallés, E.M. Polym Bull 1995, 35, 279-284.

9. Thomas, D.R. In Siloxane Polymers, Carson, S.J. and Semlyen, J.A. (ed), 1993, PTR Prentice Hall: Englewood Cliffs, NJ, 1993; Ch. 12.

10. Batch, G.L.; Macosko, C.W.; Kemp, D.N. Rubber Chem Techn 1991, 64, 218233.

11. Simpson T.R.E.; Parbhoo B.; Keddie J.L. Polymer, 2003, 44, 4829-4838.

12. Roseler, A.; Korte, E.-H. Thin Solid Films 1998, 313-314, 708-712.

13. Tsankov, D.; Hinrichs, K.; Röseler, A.; Korte, E.H. Phys Stat Sol A 2001, 188, 1319-1329.

14. Jones R.A.L.; Richards R.W. Polymers at Surfaces and Interfaces; Cambridge University Press: Cambridge,1999.

15. Botter, W.; Ferreira Soares, R.; Galembeck, F. J. Adhesion Sci Technol 1992, 6, 791-805.

16. Williams, D.H.; Fleming, I. Spectroscopic Methods in Organic Chemistry, $4^{\text {th }}$ Ed., McGraw-Hill: New York, 1989, pp. 29-62.

17. Anderson, D.R. In Analysis of Silicones, Smith, A.L. (ed); John Wiley \& Sons: London, 1974, Ch. 10.

18. Podoba, A.M.; Goldovskii, E.A.; Donstov, A.A. Intern Polym Sci Tech 1987, 14, T/42-45.

19. Chu, W. K.; Mayer, J. W.; Nicolet, M. A. Backscattering Spectrometry, Academic Press: New York, 1978.

20. Jeynes, C.; Barradas, N.P.; Marriott, P.K.; Boudreault, G.; Jenkin, M.; Wendler, E.; Webb, R.P.; J. Phys. D: Appl. Phys. 2003, 36, R97-R126. 
Published in Journal of Polymer Science: Polymer Chemistry (2004) 42: 1421-1431

21. Owens, D.K.; Wendt, R.C. J. Appl. Polym. Sci. 1969, 13, 1741-1747.

22. Bower, D.I.; Maddams, W.F. The Vibrational Spectroscopy of Polymers,

Cambridge University Press, Cambridge, 1992, pp. 194-200.

23. Parbhoo, B.; Izrael, S.; Salamanca, J.M.; Keddie, J.L. Surf Interf Anal 2000, 29, 341-345.

24. Aspnes, D.E. Phys Rev B 1986, 33, 677-682.

25. Greenwood, N.N.; Earnshaw, A. Chemistry of the Elements, Pergamon Press, Oxford, 1990.

26. Chandra, G.; Lo, P.Y.; Hitchcock, P.B.; Lappert, M.F. Organometallics 1987, 6, 91.

27. Lewis, L.N.; Lewis, N. J. Am. Chem. Soc. 1986, 108, 7228-7231. 
Published in Journal of Polymer Science: Polymer Chemistry (2004) 42: 1421-1431

Table 1. First-Order Reaction Coefficient, $k_{1}$, for the Consumption of $\mathrm{SiH}$ in the Crosslinking Reaction in $7 \mu \mathrm{m}$ PDMS Silicone Coatings at Room Temperature

\begin{tabular}{|c|c|}
\hline Substrate & $\boldsymbol{k}_{\mathbf{1}}\left(\mathbf{1 0}^{\mathbf{- 5}} \mathbf{s}^{\mathbf{- 1}}\right)$ \\
\hline $\mathrm{SiO}_{2} / \mathrm{Si}$ & $236 \pm 77$ \\
\hline $\mathrm{PET}$ & $245 \pm 77$ \\
\hline PS & $215 \pm 77$ \\
\hline
\end{tabular}


Published in Journal of Polymer Science: Polymer Chemistry (2004) 42: 1421-1431

Table 2. First-Order Reaction Coefficient, $k_{1}$, for the Consumption of $\mathrm{SiH}$ in the Post-Cure Reaction in $2.5 \mu \mathrm{m}$ PDMS Coatings at $80{ }^{\circ} \mathrm{C}$

\begin{tabular}{|c|c|}
\hline Substrate & $\boldsymbol{k}_{\mathbf{1}}\left(\mathbf{1 0}^{-5} \mathbf{s}^{\mathbf{- 1}}\right)$ \\
\hline $\mathrm{SiO}_{2} / \mathrm{Si}$ & $107 \pm 19$ \\
\hline $\mathrm{PET}$ & $344 \pm 62$ \\
\hline PS & $712 \pm 128$ \\
\hline PDMS & $1580 \pm 284$ \\
\hline
\end{tabular}


Published in Journal of Polymer Science: Polymer Chemistry (2004) 42: 1421-1431

Table 3. Interfacial Concentrations of Excess Pt in $2.5 \mu \mathrm{m}$ Silicone Coatings as Determined by Rutherford Backscattering Spectrometry over a $270 \mathrm{~nm}$ Interfacial Region

\begin{tabular}{|l|c|c|c|}
\hline Substrate & SiH:SiVi & $\begin{array}{c}\text { Temperature } \\
\left.\mathbf{(}{ }^{\mathbf{}} \mathbf{C}\right)\end{array}$ & $\begin{array}{r}\text { Interfacial Excess Areal Density } \\
\text { of Pt } \mathbf{( 1 0}^{\mathbf{1 2}} \mathbf{a t o m s ~} \mathbf{~ c m}^{\mathbf{2}} \mathbf{)}\end{array}$ \\
\hline $\mathrm{SiO}_{2} / \mathrm{Si}$ & $1: 1$ & 25 & $10.2 \pm 2.2$ \\
\hline $\mathrm{PS}$ & $1: 1$ & 25 & $0 \pm 2.9$ \\
\hline $\mathrm{SiO}_{2} / \mathrm{Si}$ & $3.2: 1$ & 80 & $8.5 \pm 2.2$ \\
\hline $\mathrm{PS}$ & $3.2: 1$ & 80 & $7.4 \pm 2.9$ \\
\hline
\end{tabular}


Published in Journal of Polymer Science: Polymer Chemistry (2004) 42: 1421-1431

Table 4. Surface Energy $(\gamma)$ of Substrates and its Polar $\left(\gamma_{P}\right)$ and Dispersive $\left(\gamma_{D}\right)$ Contributions

\begin{tabular}{|l|c|c|c|}
\hline Substrate & $\gamma_{\mathrm{P}}\left(\mathrm{mJ} \mathrm{m}^{-2}\right)$ & $\gamma_{\mathrm{D}}\left(\mathrm{mJ} \mathrm{m}^{-2}\right)$ & $\gamma\left(\mathrm{mJ} \mathrm{m}^{-2}\right)$ \\
\hline $\mathrm{SiO}_{2} / \mathrm{Si}$ & $27 \pm 1$ & $23 \pm 1$ & $50 \pm 1$ \\
\hline PET & $8 \pm 2$ & $41 \pm 1$ & $49 \pm 1$ \\
\hline PS & $1 \pm 1$ & $42 \pm 1$ & $43 \pm 1$ \\
\hline PDMS & $0 \pm 0$ & $21 \pm 1$ & $21 \pm 1$ \\
\hline
\end{tabular}




\section{Figures}
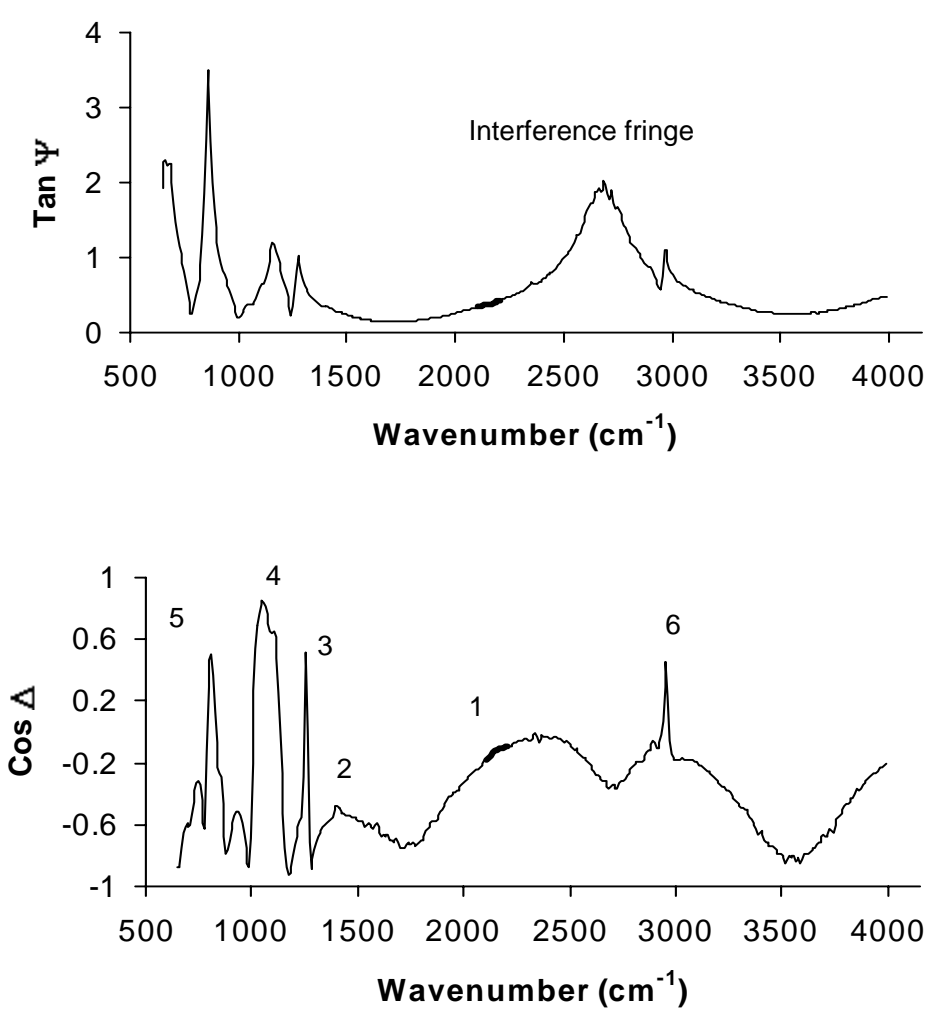

Figure 1. Ellipsometry spectra ( $\tan \psi$ and $\cos \Delta$ ) obtained from a $2.6 \mu \mathrm{m}$ silicone coating on a PS substrate at the start of crosslinking at $80{ }^{\circ} \mathrm{C}$. An interference fringe can be observed in the tan $\psi$ spectrum. The SiH stretching mode (1) of the crosslinker is apparent in the spectrum at about $2150 \mathrm{~cm}^{-1}$, as indicated with the heavy line. The other bands in the spectrum are the asymmetric $\left(2: 1400 \mathrm{~cm}^{-1}\right)$ and symmetric (3: $\left.1250 \mathrm{~cm}^{-1}\right) \mathrm{CH}_{3}$ deformations, Si-O-Si stretch (4: $\left.1000-1100 \mathrm{~cm}^{-1}\right), \mathrm{CH}_{3}$ rock/Si-C stretch (5: $750-870 \mathrm{~cm}^{-1}$ ) and asymmetric $\mathrm{CH}_{3}$ stretch (6: $2954 \mathrm{~cm}^{-1}$ ) 

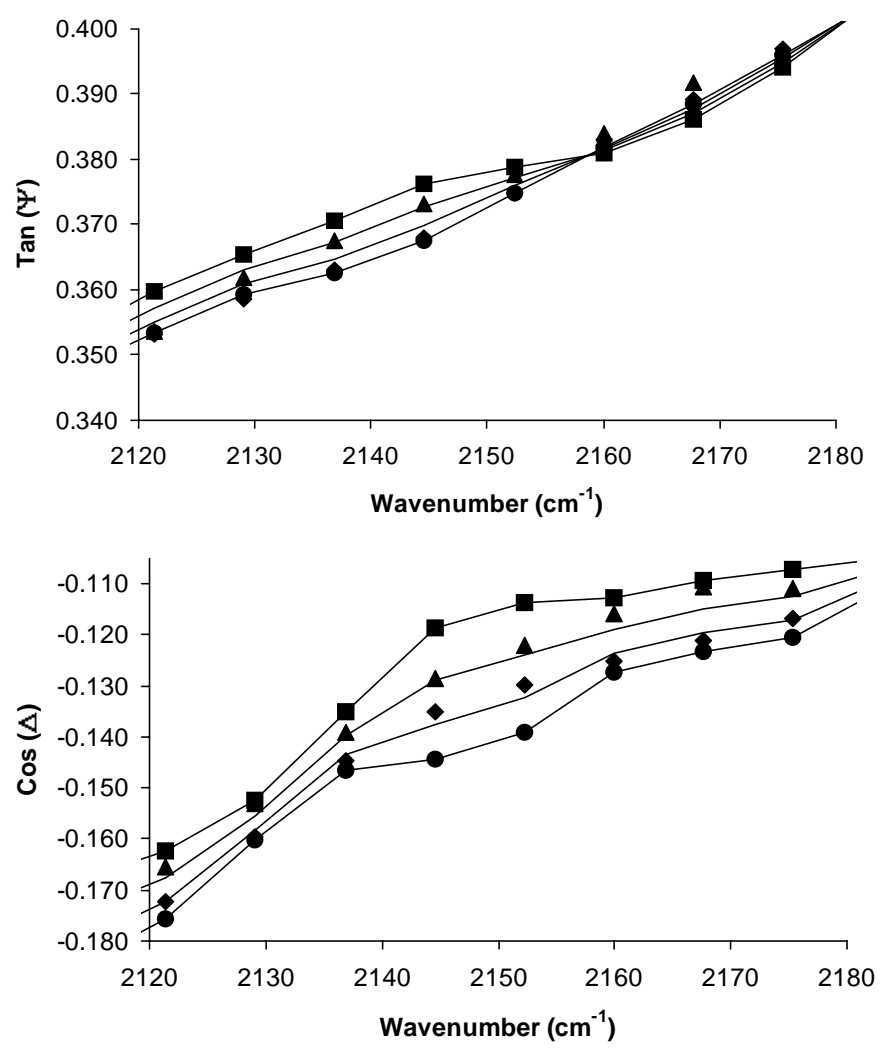

Figure 2. A series of $\tan \psi$ and $\cos \Delta$ spectra obtained after various times of crosslinking of a $2.6 \mu \mathrm{m}$ coating on a PS substrate at $80^{\circ} \mathrm{C}$. The times shown are 0 $(\boldsymbol{\square}), 0.6(\sigma), 2.9(\bullet), 5.3(\bullet) \mathrm{min}$. The solid lines show the best fit to the data using an EMA model, corresponding to $0 \%, 40 \%, 74 \%$, and $100 \%$ consumption of $\mathrm{SiH}$ (in chronological order). 


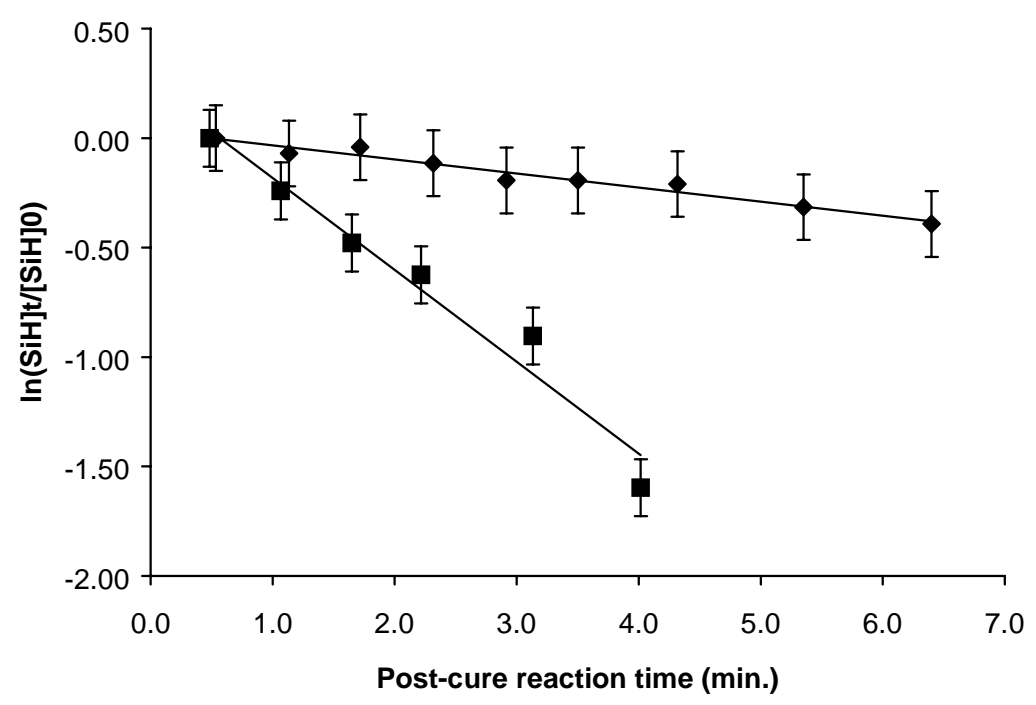

Figure 3. The dependence of $\ln \left([\mathrm{SiH}]_{t} /[\mathrm{SiH}]_{0}\right.$ on the cure reaction time for silicone coatings of similar thickness $(\sim 2.5 \mu \mathrm{m})$ on $\mathrm{SiO}_{2} / \mathrm{Si}(\bullet)$ and PS $(\boldsymbol{\square})$ substrates at 80 ${ }^{\circ} \mathrm{C}$. The initial SiH:SiVi ratio is 3.2:1. The lines are the linear best fits to the data. The gradients of these lines give the first-order reaction coefficients $\left(k_{1}\right)$ for the cure reaction. The $\mathrm{SiO}_{2} / \mathrm{Si}$ data were reported previously [11], but is re-plotted here for the sake of easy comparison. 


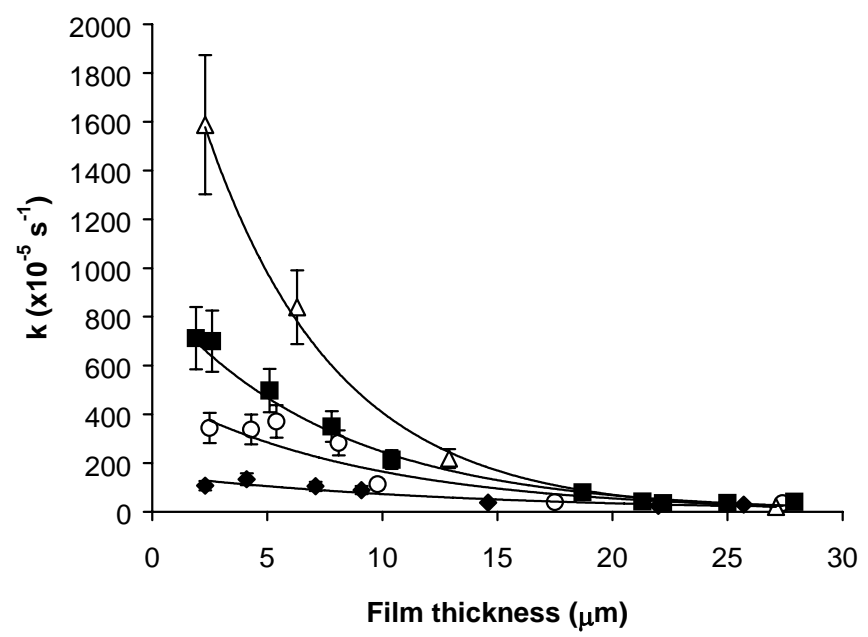

Figure 4. The reaction coefficient for the cure reaction, $k_{1}$, at $80{ }^{\circ} \mathrm{C}$ as a function of the thickness of silicone coatings on four different types of substrate: Si $(\diamond)$, PET (O), PS ( $\mathbf{\square})$ and PDMS $(\Delta)$. The solid lines are guides to the eye. 